\title{
Depth Profiling (ICP-MS) Study of Trace Metal 'Grains' in Solid Asphaltenes
}

\author{
Avin E. Pillay, ${ }^{1}$ Ghada Bassioni, ${ }^{2,4}$ Sasi Stephen, ${ }^{1}$ Fritz E. Kühn ${ }^{3}$ \\ ${ }^{1}$ Department of Chemistry, The Petroleum Institute, Abu Dhabi, UAE \\ ${ }^{2}$ Chemical Engineering Department, The Petroleum Institute, Abu Dhabi, UAE \\ ${ }^{3}$ Inorganic Chemistry/Molecular Catalysis, Catalysis Research Center, Technische Universität München, Ernst-Otto-Fischer- \\ Str 1, Garching bei München, Germany \\ ${ }^{4}$ Chemistry Department, Faculty of Engineering, Ain Shams University, Cairo, Egypt
}

\begin{abstract}
Knowledge of trace metal 'grains' in asphaltenes could play a significant role in enhancing refining and processing of crudes and also in providing useful information on mechanistic and migratory features linked to asphaltenes. These metals originate directly from interaction of oils with source-rock, mineral matter, and formation water and their accumulation in asphaltene matrices could vary from oil well to oil well. Suitable asphaltene samples were subjected to highperformance ICP-MS laser depth profiling $(213 \mathrm{~nm})$ to depths of $50 \mu \mathrm{m}$ at $5 \mu \mathrm{m}$ intervals. The study was conducted in the absence of standardization and characteristic intensities originating from the metals of interest were measured. Ten metal profiles were investigated ( $\mathrm{Na}, \mathrm{Mg}, \mathrm{Al}, \mathrm{Mn}$, $\mathrm{Fe}, \mathrm{Zn}, \mathrm{Sr}, \mathrm{Pb}, \mathrm{V}$, and $\mathrm{Ni}$ ). The experimental results showed non-uniform distribution of trace metals and identified areas where such metals agglomerate. The data suggested that certain chemical and physical conditions within the structure of asphaltenes are favorable for metal 'grain' formation at specific points. The exact mechanism for this behavior is not clear at this stage, and has considerable scope for future studies, including mathematical modeling simulations of asphaltenes. We also found that solid asphaltenes could be a useful forerunner of scale formation.
\end{abstract}

Key words: ICP-MS, Asphaltenes, Trace metal 'grains', Laser ablation, Scales

\section{Introduction}

A sphaltenes are organic substances that are present in crude oil. It is known that heavy metals accumulate in asphaltenes and tend to form metal porphyrins (or metalloporphyrins) [1-5]. Knowledge of asphaltenes is still scant and much research is necessary to unravel their complex-

Electronic supplementary material The online version of this article (doi:10.1007/s13361-011-0157-1) contains supplementary material, which is available to authorized users.

Correspondence to: Avin E. Pillay; e-mail: apillay@pi.ac.ae, Ghada Bassioni; e-mail: gbassioni@pi.ac.ae ities. Extensive studies have been conducted on metalloporphyrins in petroleum, and it is known that crude oil containing large amounts of heavy metals tend to have several adverse effects on equipment and refining processes [1]. Demetallization of crudes is therefore vital to prevent such deleterious effects [1]. However, such demetallization has primarily focused on the existence of these heavy metals in the form of metal porphyrins. Our study has shown that there is a distinct possibility that such metals could also exist as 'grain-type structures' within the hydrocarbon matrix [6]. Therefore, treatment of asphaltenes in terms of demetallization and in other processes could change on this basis. Organometallic structures of similar nature are well known, and of increasing interest in various areas of chemistry [7-14]. The existence of such metal 'grains' at random points in the 
asphaltene matrix is unexplored and could open up a new area of study and interesting possibilities, for example using the metal-containing asphaltene as in situ catalysts for workup procedures [15]. This paper is based on laser depth-profiling of asphaltenes. Laser ablation technology [coupled to inductively coupled plasma mass spectroscopy (ICP-MS)] uses a microbeam to ablate samples in a special sample chamber $[16,17]$. The fine ablated material is transported to a hot plasma where it is atomized and converted to ions (characteristic of the elements of the sample), which are subsequently carried to a mass spectrometer for detection. The technique is highly sensitive [18] and can attain a limit of detection of $10^{-6} \mathrm{mg} / \mathrm{kg}$ (parts per trillion) for most elements. Laser ablation technology is capable of depth and surface analysis and produces an elemental profile.

We observed from the experimental data that depending on the conditions within the hydrocarbon matrix, heavy metals could possibly exist in three forms: either as isloated inclusions, as metalloporphyrins, or as metal 'grains.' The reason such metal structures eluded scientists using X-ray structural analysis and similar techniques was possibly because they occur randomly at ultra trace levels and are 'shadowed' by invasive inclusions and metalloporphyrins. Our work with laser micro-beam depth profiling ICP-MS suggests that the presence of these metal 'grains' in asphaltenes would distinctly influence the chemistry of crude oil treatment and play a role in future research in this area.

\section{Materials and Methods}

\section{Instrumentation/Sample Handling}

Asphaltene samples (Figure 1a) collected from a carbonate oil reservoir in the Arabian Gulf were suitably labeled and random points on their top and bottom surfaces were examined with the laser. No serious sample treatment was necessary prior to irradiation. Samples were investigated with a Perkin Elmer SCIEX DRC-e ICP-MS (Ontario, Canada) fitted with a New Wave UP-213 laser ablation system (Figure 1b). The samples were placed in a special sample holder with dimensions $5 \mathrm{~cm} \times$ $5 \mathrm{~cm}$. Samples were subjected to 213-nm laser irradiation with a repetition rate of $4 \mathrm{~Hz}$ (pulsed beam); the level of the beam energy was $45 \%$, with a beam diameter of $100 \mu \mathrm{m}$. The laser gas flow was $0.80 \mathrm{~L} / \mathrm{min}$. It was programmed to continuously ablate successive depths of $5 \mu \mathrm{m}$ at each point and 'drilled' through the sample to a total depth of $50 \mu \mathrm{m}$. Due to the inhomogeneous nature of the samples, the depth-profiling process itself was uncalibrated and the plotted profiles recorded for each measurement were graduated for convenience.

\section{Spectral Analysis/Validation of the Technique}

Characteristic intensities originating from the metals of interest were measured; and valid considerations were given to potential interferences and matrix effects [19]. Prior to each run, the instrument underwent appropriate calibration and correction for background [20]. The study was largely semiquantitative in the absence of standardization, and for the purposes of comparison, all measurements were conducted under identical experimental conditions. Signal intensities were compared at different depths in the bulk of the sample, and appropriate spectra were produced to observe fluctuations in characteristic metal intensity.

Solid standards of matching matrix are generally not available, and the only suitable means of validating the analytical performance of the laser technique was to examine an available certified standard, which in our case was a glass bead (NIST, Certificate 613). We thus examined the analytical performance of the instrument by taking replicate measurements $(n=3)$ for equivalent counting times at random points on the glass standard. Relative standard deviations of less than $5 \%$ were attained (Table 1), indicating that the operational performance of the facility was satisfactory. It is necessary to underscore that in the absence of matching matrix standards, the analysis of the certified glass standard served mainly to demonstrate the precision of the method in a homogeneous material.

\section{Results and Discussion}

\section{Trace Metal 'Grains', Inclusions, and Metalloporphyrins}

Depth-Profiling: is an ultra-sensitive tool that has the capability of 'drilling' through samples and obtaining relevant information on the distribution of trace metals. The technique is semiquantitative and capable of high-resolution detection over a wide range of elemental levels. Contemporary methods, like XRF, are popular but lack the ability to control depth penetration. Charged particle irradiation is useful, but such techniques require nuclear accelerators, and tend to be limited
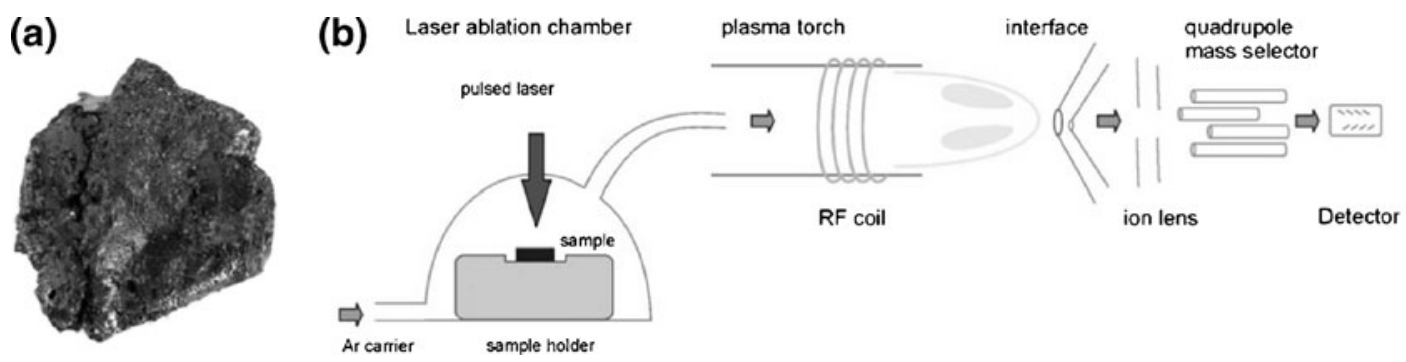

Figure 1. (a) Typical asphaltene sample subjected to ICP-MS analysis. (b) The ICP-MS instrument and laser set-up used for sample irradiation 
Table 1. Measurements (counts/s) of Reproducibility in a Glass Standard

\begin{tabular}{|c|c|c|c|c|c|c|}
\hline Measurement & ${ }^{59} \mathrm{Co}$ & ${ }^{85} \mathrm{Rb}$ & ${ }^{88} \mathrm{Sr}$ & ${ }^{138} \mathrm{Ba}$ & ${ }^{140} \mathrm{Ce}$ & ${ }^{238} \mathrm{U}$ \\
\hline 1 & 503 & 718 & 3688 & 1618 & 1023 & 1805 \\
\hline 2 & 511 & 736 & 3672 & 1624 & 1141 & 1814 \\
\hline 3 & 491 & 735 & 3587 & 1620 & 1036 & 1792 \\
\hline Mean \pm RSD & $502 \pm 1.6 \%$ & $730 \pm 1.1 \%$ & $3649 \pm 1.2 \%$ & $1621 \pm 0.15 \%$ & $1067 \pm 4.95 \%$ & $1804 \pm 0.50 \%$ \\
\hline
\end{tabular}

to only a few microns below the surface, as is also the case with secondary ion mass spectrometry (SIMS). The capability, therefore, of ablative laser technology to penetrate to controlled depths below the surface of a sample is attractive for a variety of studies in bulk materials. It is imperative to emphasize that this investigation was conducted in the absence of reference standards, for the obvious reason that it was not possible to obtain suitable standards to match the highly inhomogeneous matrix of asphaltenes. The results are therefore relative and compared in terms of intensities (counts/s).

Trace Metal 'grains': From spectral information obtained in this study, there is strong evidence to suggest that in some cases trace metals in asphaltenes occur in 'grain-type' formations (possibly linked to alkene, nitrogen, oxygen, and sulphur donors) [6]. At this point, it is necessary to emphasize that literature values of intermetallic distances [7] in metalloporphyrins are generally $<1 \mu \mathrm{m}$. Our beam diameter was $100 \mu \mathrm{m}$ with a depth-profiling interval of $5 \mu \mathrm{m}$, both of which cover considerable breadth and depth on the nanoscale. As a result, several trace metals were expected to be detected in a single laser shot. We surmised that it was unlikely for spectra to 'mirror' or 'mimic' each other simply because there was no justifiable reason why they should. However, our data revealed that spectral trends for some metals 'mirrored' each other. This was unexpected and the only viable explanation was that some intrinsic structural consistency characterized these spectral features. Figure 2a represents typical depth-profiles of $\mathrm{Na}$ and $\mathrm{Mg}$, from a single ablated point. Clearly, both profiles are a perfect 'fit', suggesting that both metals are concomitantly present in the same grain with strong points of similarities in their structural arrangements in the hydrocarbon matrix. The intervals between peaks were ascribed to non-metallic components of the matrix (carbon, nitrogen, oxygen, sulphur), which are not shown. The presence of dual peaks was ascribed to the 'waxiness' of the matrix, which was ductile and easily fragmented in the laser
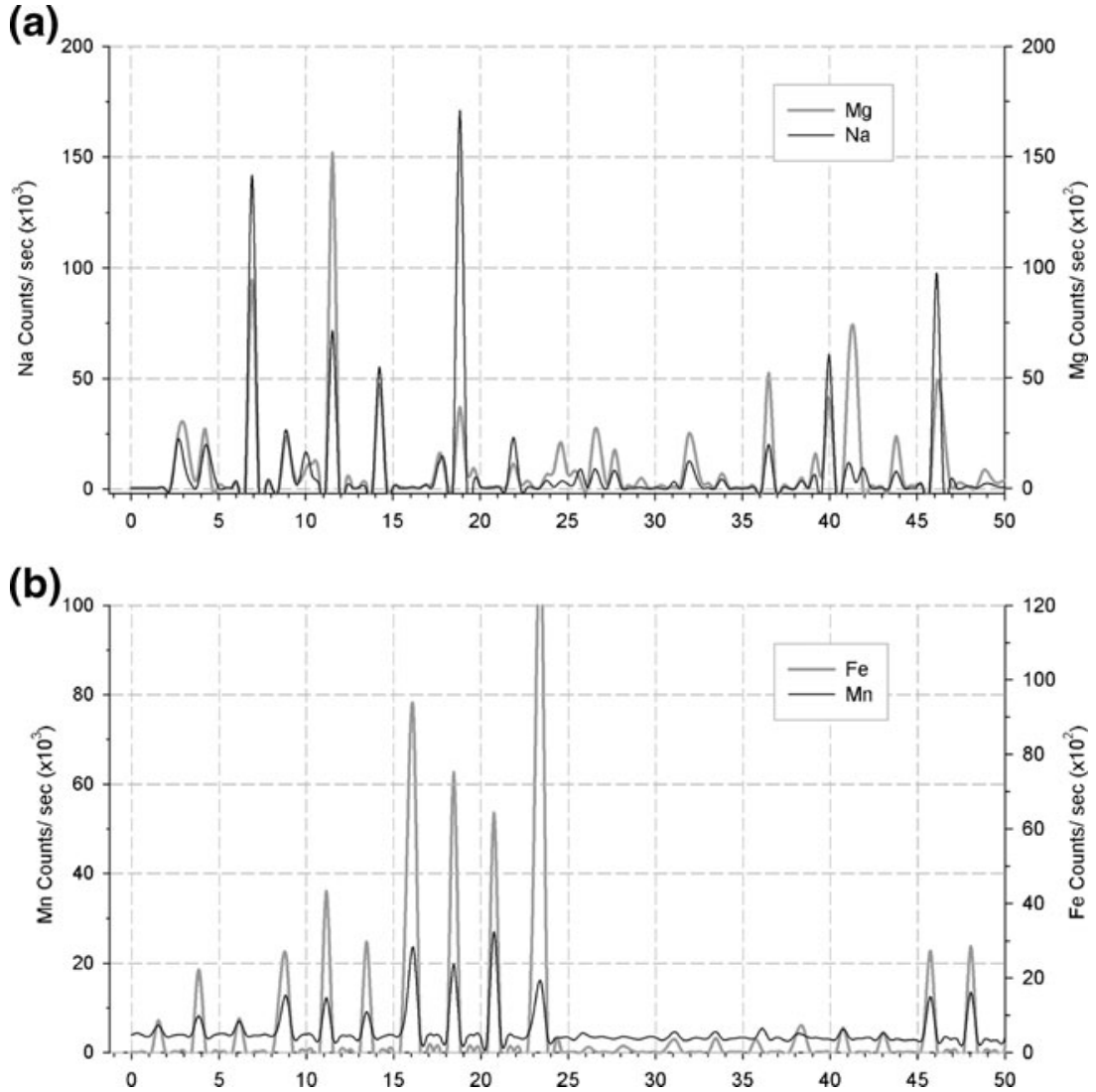

Figure 2. (a) Depth-profiling plots of $\mathrm{Na} / \mathrm{Mg}$. (b) Depth-profiling plots of $\mathrm{Mn} / \mathrm{Fe}$ 
beam. The sharp variation in intensity from depth to depth was attributed again to the instability of the matrix and slight variations in the density of the sample. Of significance is the fact that the intensities of $\mathrm{Na}$ far exceed those for $\mathrm{Mg}$ in Figure $2 \mathrm{a}$, which clearly suggests a preponderance of $\mathrm{Na}$ atoms in the 'grains'.

Further evidence of matching spectra appears in Figure $2 \mathrm{~b}$ showing $\mathrm{Mn}$ and $\mathrm{Fe}$ assignments (single ablated spot, different sample) that are veritable 'fingerprints' of each other. The $\mathrm{Fe}$ intensities are several hundred times higher than those of Mn, suggesting that in a single molecule there is possibly a 'football' of $\mathrm{Fe}$ atoms linked to a 'golfball' clump of Mn atoms. With the exception of differential intensities, the perfect 'fit' of the $\mathrm{Mn}-\mathrm{Fe}$ profiles in Figure $2 \mathrm{~b}$ point strongly to the possible existence of metal 'grain' complexes. Figure 3a (overlaid profiles of Mn, Fe, and $\mathrm{Zn}$ from another ablated spot, same sample), is yet another excellent example of profiles that are 'in phase' with each other. The features in Figure 3a portray the presence of a triple-transition metal 'grain' complex, whose properties would obviously differ from those of the $\mathrm{Na} / \mathrm{Mg}$ 'grain' complex delineated in Figure 2a. One of the main features of Figure $3 \mathrm{a}$ is that intensities drop to negligible levels at depths between 10 and $25 \mu \mathrm{m}$. The absence or lack of $\mathrm{Mn}$ and $\mathrm{Zn}$ at these points could signify depleted levels of these analytes in the matrix.
The most common trace metals in asphaltenes are $\mathrm{V}$ and Ni. Figure S1 (depth-profiles of these two metals, single ablated spot) indicates that the resemblance between them is strong although the Ni profile depicts three sharp assignments at about 16,21, and $23 \mu \mathrm{m}$, which are absent in the $\mathrm{V}$ profile. These isolated Ni lines could signify either nickel inclusions or isolated nickel-porphyrins. The match between the profiles at depths of $0-16 \mu \mathrm{m}$ and $36-48 \mu \mathrm{m}$ reflects the possibility of V/Ni 'grain' complexes. The $\mathrm{V}$ profile looks 'wobbly' between 20 and $35 \mu \mathrm{m}$, which, once again, could be due to matrix instability or other unknown interferences in the environment of $\mathrm{V}$-not present in the vicinity of $\mathrm{Ni}$.

Metalloporphyrins: Spectral patterns that consistently recur (but not necessarily 'in phase' with each another) were attributed to the presence of metal porphyrins. Figure $3 \mathrm{~b}$ (depth-profiles of $\mathrm{Pb}$ and $\mathrm{Al}$, single ablated point) shows distinctly that their patterns resemble each other, but do not 'fit' as shown in Figure 2a, 2b and 3a. The spacing between peaks in individual profiles is roughly $7-8 \mu \mathrm{m}$ and between peaks in the overlay $<1 \mu \mathrm{m}$, suggesting that these metals occur in an array of metalloporphyrins. The broadness of some peaks was ascribed to the instability of the tar-like matrix, which was conducive to the creation of shrapnel in the wake of bigger ablated fragments. The presence of 'humps' or little peaks appearing on the shoulders of strong peaks could also be attributed to this effect.

(a)

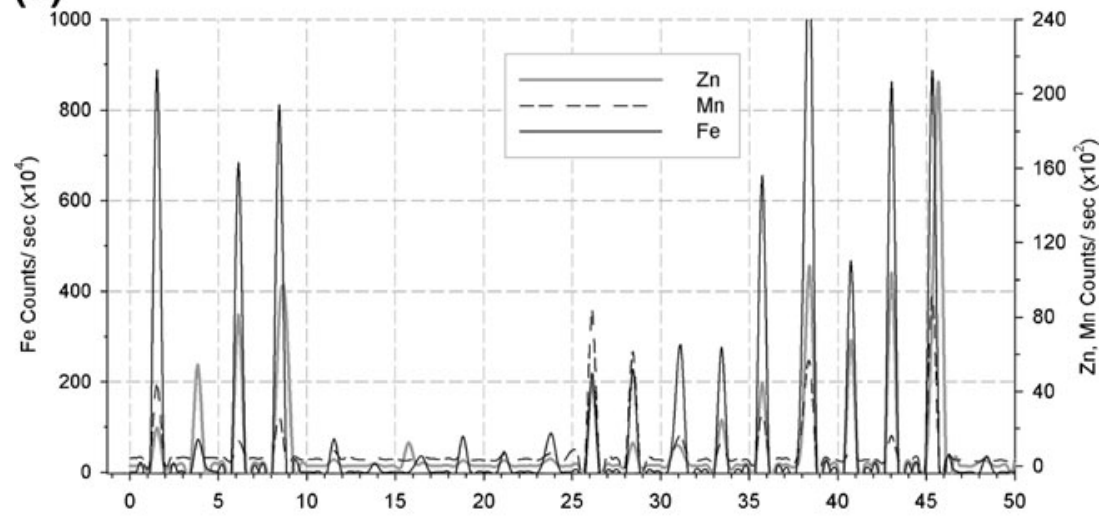

(b)

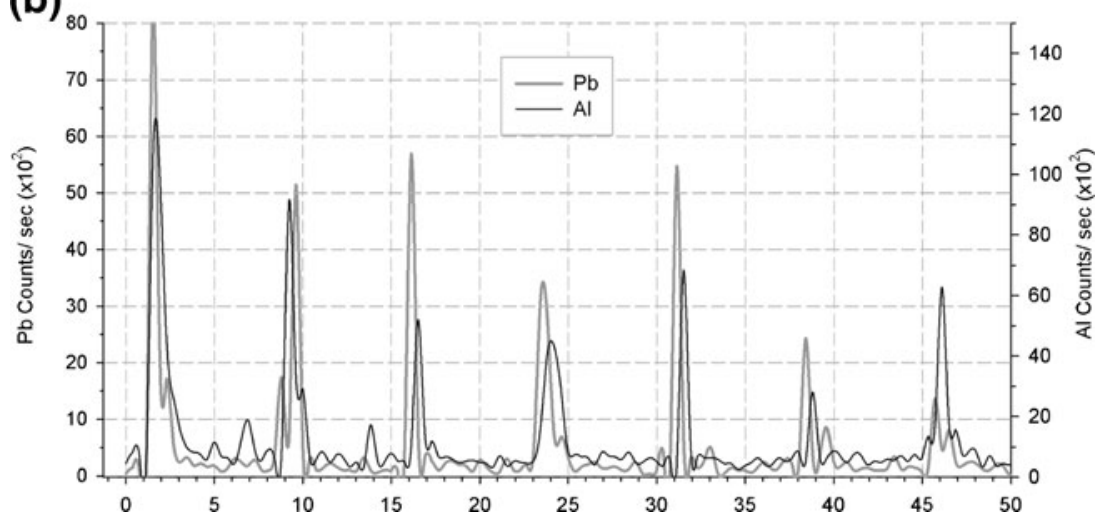

Figure 3. (a) Depth profiling plots of $\mathrm{Zn} / \mathrm{Mn} / \mathrm{Fe}$. (b) Depth-profiling plots of $\mathrm{Pb} / \mathrm{Al}$ 
Inclusions: Examples of possible isolated metal inclusions are reflected in patterns that do not match, for instance, Figure $\mathrm{S} 2$, where overlaid profiles of $\mathrm{Na}, \mathrm{Zn}$, and $\mathrm{Al}$ (single ablated point) clearly indicate from the appearance of solitary peaks that these metals occupy isolated positions in the asphaltene matrix. In this particular case there seems to be no link at all among these metals and it would thus be reasonable to assume that these 'hotspots' provide no evidence of metallic 'grain' formation but, instead, are clear examples of trace metal inclusions.

\section{Prediction of Scale Formation}

Solid asphaltenes could be considered a harbinger of strontium scale formation [21]. Strontium sulphate scale deposition is a common problem in hydrocarbon producing wells and reservoirs. Seawater (relatively abundant in sulphates) is injected into these wells for pressure maintenance, and combines with formation brines that contain appreciable levels of strontium. Scale formation near wellbore locations is accelerated because of significant and favorable changes of pressure and temperature at these sites. Progressive and undesirable congestion by scale deposits tends to reduce the production of oil and gas [22]. Figure $\mathrm{S} 3$ is a depth-profile of $\mathrm{Sr}$ indicating that it appears at appreciable intensities at different depths. Solid asphaltenes could, therefore, be a good indicator of the outbreak of corrosion by scales. Detection of $\mathrm{Sr}$ in solid asphaltenes by ablative laser technology is quick and simple, and has not been previously reported. It could signal the onset of scaling problems and prompt remedial measures.

\section{Impact of Our Findings}

The adverse effects of metals in petroleum are well known [13]. Combustion of heavy fuel oils in refinery furnaces and boilers can leave an undesirable residuum of trace metal oxides in furnace boxes and other equipment. In addition, it is highly desirable to remove metal contaminants before treatment as they can poison certain catalysts. They also affect the cracking process and could alter the structure of catalysts used. Metals such as nickel, iron, and vanadium are present in crude oils at low levels and are removed during the refining process. The demetallization of crude oil includes physical, chemical and catalytic treatment processes. Until now, researchers in petroleum studies envisaged accumulation of heavy metals in asphaltenes only in the form of metalloporphyrins and isolated inclusions. Our study has shown that, in addition, heavy metals can occur in metal 'grain-type' complexes [6]. Clearly, certain chemical and physical conditions within the structure of asphaltenes favor 'grain' formation. The mechanism governing this behavior is unclear and is a subject for future study. Therefore, in view of this, treatment of crude oils and residuum fractions should be revised for effective removal of metallic 'grains'. Such revision could involve adapting physical and chemical processes and renewed catalytic treatment. In treating such metallic 'grain' structures, properties such as isomerism, magnetism, electronic characteristics, and reactivity have to be collectively taken into account. Deasphalting of crude oil residues could, therefore, be made more efficient in light of our findings by considering extraction of a combination of metalloporphyrins and metal 'grain' complexes. In addition, the technique could be useful in measuring the dimensions of metal 'grains' in pure samples. The potential environmental impact of our study should also be carefully considered. Marine organisms and birds exposed to asphaltenes following deepwater oil spills could ingest a splurge of trace metal 'grains', which would dramatically elevate their biological trace metal concentrations.

\section{Conclusions}

Our study shows that the microstructure of asphaltenes is exceedingly complex. To successfully implement trace metal demetallization of crude oil residues, consideration must be given to the existence of three types of trace metal formations: metalloporphyrins, inclusions, and metal 'grain' complexes. Metal 'grain' formations necessitate adapting physical, chemical, and other refining processes for the most efficient removal of trace metals. Knowledge of the properties of metal 'grains', such as isomerism, magnetism, and reactivity will be helpful in their extraction from crude oil residues. The presence of such complexes in solid asphaltenes lends scope to advances in organometallic chemistry and areas of nanotechnology. The ICP-MS ablative technique could also be helpful in evaluating the dimensions of 'grains' in pure metal 'grain-type' complexes.

\section{References}

1. Gould, K.A.: Oxidative demetallization of petroleum asphaltenes and residua. Fuel 59, 733-736 (1980)

2. Rocha, L.C., Ferreira, M.S., da Silva, A.C.: Wettability alteration of internal surfaces of pipelines for use in the transportation of heavy oil via core-flow. J. Petr. Sci. Eng 51, 26-36 (2006)

3. Verdier, S., Plantier, F., Bessières, D., Andersen, S., Stenby, E., Carrier, H.: Study of asphaltene precipitation by Calorimetry. Energy Fuels 21, 3583-3587 (2007)

4. De Chaine, G.P., Gray, M.R.: Chemistry and association of vanadium compounds in heavy oil and bitumen, and implications for their selective removal. Energy Fuels 24, 2795-2808 (2010)

5. Yin, C.X., Stryker, J.M., Gray, M.R.: Separation of petroporphyrins from asphaltenes by chemical modification and selective affinity chromatography. Energy Fuels 23, 2600-2605 (2009)

6. Gondal, M.A., Siddiqui, M.N., Nasr, M.M.: Detection of trace metals in asphaltenes using an advanced Laser-Induced Breakdown Spectroscopy (LIBS) technique. Energy Fuels 24, 1099-1105 (2010)

7. Schmid, G., Fenske, D.: Metal clusters and nanoparticles. Phil. Trans. R. Soc. A 368, 1207-1210 (2010)

8. Braunstein, P.L., Oro, A., Raithby, P.R.: Wiley-VCH Verlag GmbH, ISBN: 9783527618316 (2008)

9. Baev, A., Rubio-Pons, O., Gel'mukhanov, F., Ågren, H.: Optical limiting properties of zinc- and platinum-based organometallic compounds. J. Phys. Chem. A 108, 7406-7416 (2004)

10. Zhang, C., Matsumoto, T., Samoc, M., Petric, S., Meng, S.C., Corkery, T.C., Stranger, R., Zhang, J.F., Humphrey, M.G., Tatsumi, K.: Dodecanuclear-ellipse and decanuclear-wheel nickel(II) Thiolato clusters with efficient femtosecond nonlinear absorption. Angew. Chem. Int. Ed. 49, 4209-4212 (2010)

11. Zhang, C., Song, Y. L., Wang, X.: Coord. Chem. Rev 251, 111-141 (2007) 
12. Zhang, C., Song, Y.L., Kühn, F.E., Wang, Y.X., Xin, X.Q.: Study on a series of pentanuclear planar 'open' clusters: synthesis, characterization, strong third-order optical nonlinearities and superior optical limiting properties. J. Mater. Chem 12, 239-248 ( 2002)

13. Zhang, C., Song, Y.L., Kühn, F.E., Xu, Y., Xin, X.Q., Fun, H.K., Herrmann, W.A.: The first assembly of a nest-shaped heterothiometallic cluster and a polyoxometalate anion-synthesis, characterization, and strong third-order nonlinear optical response. Eur. J. Inorg. Chem 5564 (2002)

14. Zhang, C., Song, Y.L., Kühn, F.E., Wang, Y.X., Fun, H., Xin, X.Q., Herrmann, W.A.: Sign alteration of the nonlinear refraction of isomorphous cubane-shaped heterothiometallic clusters originating from a skeleton atomic effect. New J. Chem 26, 58-65 ( 2002)

15. Usui, K., Kidena, K., Murata, S., Nomura, M., Trisunaryanti, W. Catalytic hydrocracking of petroleum-derived asphaltenes by transition metal-loaded zeolite catalysts. Fuel 83, 1899-1906 (2004)
16. Robinson, J.W., Skelly Frame, E.M., Frame, G.M.: Undergraduate Instrumental Analysis; Marcel Dekker: New York (2005)

17. Jarvis, K.E., Gray, A.L., Houk, R.S. Handbook of ICP-MS. Blackie Publishers, London (1992)

18. Ward, N.J.: In: Fifield, F.W., Haines, P.W. (eds.) Environmental Analytical Chemistry. Blackwell Science, Oxford, UK (2000)

19. Momma, C., Chichkov, B.N., Nolte, S., von Alvensleban, F., Tunnermann, A., Welling, H., Wellegehausen, B.: Short-pulse laser ablation of solid targets. Optics Commun 129, 134-142 (1996)

20. Perkin Elmer SCIEX, Elan Version 3-4, Software reference guide, Canada, 24 April, 2007

21. Todd, C.A., Yuan, D.M.: Barium and strontium sulfate solid-solution scale formation at elevated temperatures. SPE Production Eng 85-92 (1992)

22. Bassioni, G.: Mechanistic aspects on the influence of inorganic anion adsorption on oilfield scale inhibition by citrate. J. Petr. Sci. Eng 70, 298-301 (2010) 